\title{
The spatial and social context of television-viewing adolescents
}

\begin{abstract}
This paper studies television-viewing adolescents within their spatial and social context, using the Uses and Gratifications approach as a typology of uses. Because previous research suggested the importance of gender-based differences in both the frequency of watching TV and of content preferences, but lacked an examination of the social- and spatial-viewing contexts for boys and girls, respectively, a specific emphasis is placed on gender. Results were obtained by means of both quantitative and qualitative methods. Despite an increased privatization of television access, which is more obvious for boys than for girls, teenagers still prefer to watch TV in the domestic environment of the living room where social interaction and television-centered communication are prevalent. Overall, social interaction about television programs yields more satisfied viewers in terms of four gratification items: exploration, amusement, social inclusion and escapism.
\end{abstract}

\section{Keywords}

Television, Adolescents, Gender, Social and Spatial Viewing, Uses and Gratifications

\section{Introduction}

'New' media, such as the Internet, have been integrated and are commonly used in the daily lives of young people, but despite this tendency, recent studies on adolescents' media usage have affirmed that television viewing maintains its dominant position in today's youth's leisure time (Roe et al., 2001; Eggermont, 2006: 742). Contemporary households are progressively more media-rich than they used to be, providing a shared culture for the family, as well as a personal provision of media for teenagers in their bedrooms (Livingstone, 2002: 167). This process of growing individualization in the western world has been stimulated by cheaper and more portable domestic media and has led to a transformation from communal to personal media (Livingstone, 2007) and this phenomenon appears to be a European and North American one, dependent on the degree of modernization and wealth (Bovill and Livingstone, 2001). Johnsson-Smaragdi et al. (1998) found the overall similarities between European countries in terms of media access, ownership and usage far more striking than the differences. For example, recent representative figures on Flanders, the Northern part of Belgium, show that $97 \%$ of Flemish households own a television set, $92 \%$ have a cell phone, $81 \%$ own a computer, and $78 \%$ have an Internet connection, which is comparable to other European countries (IBBT, 2009). Therefore, Flanders, as a region in Western Europe, can function as a case study within this European TV-viewing context (Roe, 2000).

According to Livingstone (2002: 145), we cannot separate youth culture from music, computer games and chat rooms, and multiple-screen homes have become increasingly commonplace. It is impossible to segregate TV from other media because today's youth is increasingly a multi-mediated generation, which is why we focus on television within the everyday-life context of global-media usage (Silverstone, 2002). The usage of mass media should, however, not be analyzed in isolation, since media are often positioned within the context of general relationships between human beings and their environment. Or as Van Rompaey (2002: 211) concluded Information and Communication Technologies (hereafter: ICT) "[...] is embedded in family dynamics and as such is able to have implications for family life." In the light of a fast moving media landscape, we studied television-viewing teenagers (aged 14-19) within their spatial 
and social context, using the Uses and Gratifications (hereafter: U\&G) approach as a typology of uses. In other words, with 'spatial and social contexts' we mean 'where' and 'with whom' adolescents watch television. Following Ruggiero (2000: 12), the U\&G approach does not provide what some scholars would consider a refined theoretical perspective, however, it "[...] furnishes a benchmark base of data for other studies to further examine media use." In doing so, we address the major lack of contextual and social factors, seen as limitations of this approach. This paper, based on data obtained by means of quantitative surveys $(\mathrm{N}=1555)$, first inquires as to the context of general media use, then takes a closer look at teenagers' television-viewing gratification items and finally elaborates on the spatial and social context of watching TV. Previous research (Roe, 2000; Roberts and Foehr, 2008) indicated gender-based differences in both quantity and content preferences in late childhood and early adolescence, but socialand spatial-viewing gender differences have not yet been examined. That is why a specific emphasis is placed on gender within the context of spatial and social TV-viewing. Or, as Roe (2000: 16) says, "[...] it is one of the most fundamentally differentiating factors in media use". By subjecting our data to a Latent Class Analysis, the identification of gender-based differences within the spatial and social context of TVviewing adolescents is achieved. These quantitative results will be complemented and validated with an in-depth systematic analysis of six focus group interviews $(\mathrm{N}=34)$ with teenagers. Consequently, this paper combines the strengths of survey data with the richness of group interviews.

\section{The Uses and Gratification typology as a starting point for further research}

In the 1970s, as a reaction to traditional mass-communication research emphasizing the effects between sender, message and receiver, U\&G theory was re-oriented to stress active, goal-oriented audiences and media users. It starts from the premise that media users get involved in particular types of mediated communications because they seek certain types of psychological or social gratification and presents an understanding of how audience motivation, individual characteristics and preferences relate to media behavior (Katz et al., 1973; Cooper and Tang, 2009: 401). In this context, Katz et al. (1974) distinguished five broad gratification categories for media use: cognitive needs, affective needs, personal integrative needs, social integrative needs and tension-release needs.

U\&G approaches have recognized two orientations towards media use: instrumental use entails more active and selective viewer motivation (e.g. information seeking, surveillance etc.), whereas ritualized usage means habitual, yet active use due to the need for a greater affinity for the medium itself (e.g. amusement, escapism etc.) (Katz et al., 1974). In U\&G literature, most television watching is considered as ritualistic in nature and shows substantial audience activity in decisions about whether to watch television or not, particularly concerning program or program-type preferences. Interestingly, U\&G theory also recognizes individual audience characteristics such as gender, age and economic status as important determinants of media usage (Cooper and Tang, 2009).

Nevertheless, studies in this empirical tradition put too much emphasis on the individual determinants of media usage and ignore the fact that television use is not completely free of limitations, since structural (e.g. scheduling factors) or contextual factors (e.g. availability or access to television, awareness of content options etc.) also impact the use of television (Cooper and Tang, 2009: 401). Many authors have issues with the application of the approach because of the concept of 'needs'; that is why they argue that the focal point of interest should shift to social and psychological factors as direct explanations of media behavior (Roe and Minnebo, 2007). With the emergence of computer-mediated communication, Ruggiero 
(2000: 3, 29) stresses that, in order to meet the needs of this changed twenty-first-century media landscape, expanding the traditional $U \& G$ tools and typologies is necessary. According to him, researchers have to include the $U \& G$ approach in future mass-communication theory, although they need to apply more comprehensive methodologies to explore interpersonal and qualitative aspects of mediated communication. Being aware of these limitations and following Rugierro (2000), we choose to use gratification typologies, not as an explanatory theoretical framework, but as a starting point for further more extensive research on the interpersonal social context of television viewing. Furthermore, the U\&G approach provides space for studying the audience characteristic of 'gender', which will be, following literature (see infra), our central point of interest.

\section{The place of television in a broader media context}

\section{Gendered media access in the twenty-first century}

Contemporary teenagers grow up in a multimedia environment in which the place and presence of television has been integrated into everyday life. Today's domestic environments contain a multitude of media goods and often, these media are spread throughout the house and its inhabitants (Van Rompaey and Roe, 2001; Livingstone, 2002). In 2001, a US household had 2.4 TV sets apiece and almost 99\% of all households with children were penetrated with a minimum of one TV set (Roberts and Foehr, 2008). Equal levels of penetration are found for European countries, and more specifically for our case study of Flanders. Data on private TV access indicate that in 2001, one out of three teenagers had their own TV set, and we suspect that these numbers have increased over the last few years (d'Haenens et al., 2001; Stevens, 2006). American studies (e.g. L'Engle et al., 2006) show an even higher number; namely two-thirds of adolescents having private access to a TV set in their room. Eggermont (2006: 742) even states that this amount rises to $70 \%$ in the United Kingdom. Gender differences are registered, since it was found that significantly more boys than girls have a TV set in their bedroom.

It is not only television that is dominantly present in almost every Flemish family, other 'old' media such as the radio and telephone have gained a permanent place in their mediated environment as well (d'Haenens et al., 2001). 'New' media like mobile phones and PCs with Internet access have acquired a dominant position and a private mobile phone has become a standard object in youngsters' lives. Roberts (2000) stated that in 2000, $21 \%$ of American teenagers had their own private computer, but this has increased in momentum in recent years. The Flemish study results of Stevens (2006) indicate that it is more common for a Flemish teen to have their own PC than a TV set, and more than $30 \%$ of (American) teenagers have Internet access in their bedrooms (Braun-Courville and Rojas, 2009), which gives the impression that contemporary teen bedrooms are multi-mediated. Like gendered TV access, an equal and significant tendency was found for private computer access where male teenagers are reported to have more access to a private PC than girls (d'Haenens et al., 2001; Stevens, 2006). Generally, according to Livingstone (2002), it is more common among girls than boys to have a media-poor bedroom; boys, on the other hand, tend to have a media-rich bedroom. Today's children across Europe and North America often take this media-rich home for granted, especially because of the more individualized mediated places: their bedrooms. In the contemporary media landscape that is characterized by a substantial increase in devices and an expanding convergence, can the 'old' medium television still be considered dominant and prominent in adolescents' life? This brings us to research question one:

$R Q$ 1: What is the position of TV usage within the context of youngsters' general media use? 
Media usage has become a daily routine in the lives of teenagers, resulting in habitual media usage either solely or simultaneously. American teenagers use media more than six hours a day and the expanding phenomenon of media multitasking multiplies this daily media usage to eight and a half hours, which is not extremely surprising, with so many media and so much content available (Roberts and Foehr, 2008). However, total use has remained relatively constant over the years and there is little evidence that any medium, but especially television, is being displaced by any other. TV-viewing appears to have remained relatively stable over the past fifty years with teenagers spending a little more than two hours involved with the medium daily (Marshall et al., 2006). Computer usage has increased since the introduction of the medium and a PC takes on the functions of other media. Especially for the younger audience groups, new media seem to fulfill their needs and desires in a better way and therefore take over the functions of traditional media (Van Cauwenberge et al., 2010). Computers are, for instance, used for listening to music, reading news etc. Moreover, computers emerge as a social-networking device among teenagers, with Facebook and Netlog - amongst others - fulfilling this function (Roberts and Foehr, 2008).

Television is the least-shared medium with other media, but is highly likely to be shared with a variety of non-media activities such as eating. Watching TV is most often paired with listening to music, reading, video gaming and emailing. Computers, on the other hand, are at the heart of the multitasking event (Roberts and Foehr, 2008). We can say that "[...] the choice of television and the Internet may not function as much as an 'either/or' choice as an and/because decision. This implies that viewers/users are likely to use both the Internet and television because they will function in both different and complementary ways" (Cooper and Tang, 2009: 413).

Gender does not reveal significant differences in overall media exposure, although boys and girls report different exposure rates to various individual media (Roberts and Foehr, 2008). According to Roe (2000), media are hierarchically organized in contemporary teens' lives: 'new' media have gained a certain position in their lives, next to audiovisual media and print media, although the latter is being suppressed more and more often. Research by Van Cauwenberge et al. (2010) confirms Roe's findings (2000): newspapers are the medium teenagers spent least time with, especially boys. Magazines, on the other hand, are popular with both boys and girls, but girls read magazines significantly more frequently than boys, who prefer comic books instead. Males favor 'new' media more than girls do, and they also love gaming considerably more. Girls prefer chat rooms, visiting websites and sending emails above playing (computer) games (Roberts, 2000; Roe, 2000). In contrast to the other media-related activities, there is no real consensus about the impact of gender regarding television viewing frequency. Some authors (e.g. Roe, 2000) state that boys watch television more frequently than girls, although others (d'Haenens et al., 2001) claim the activity is not gender specific. They state, however, that television viewing differs according to age and type of education (Sinnaeve et al., 2006; Marshall et al., 2006). Multitasking, on the other hand, does seem to be gendered: girls tend to multitask more than boys (Roberts and Foehr, 2008).

$R Q$ 2: Is gender an important differentiating factor in the contemporary media usage and multitasking behavior of young people? 


\section{Spatial and social context of TV viewing}

As mentioned earlier, teens have substantial access to media in their own bedrooms, which are becoming more like media-rich environments as the years progress (Van Rompaey, 2002). This bedroom culture is, according to Livingstone (2002: 161) "[...] the object of concern not because it offers privacy but because it appears to isolate young people from participation in the public (i.e. disinterested) sphere." Some even regard youngsters' bedrooms as private mediated islands or little multimedia studios and proclaim this will also lead to more privatized media use among teenagers. However, several studies (e.g. Stevens, 2006: 193-194; d'Haenens et al., 2001; Pasquier et al., 1998) repudiate this private media use and highlight that in Flanders, media are still used collectively, within the context of the family. The private mediated island "[...] may lead to more individual media use, but it does not lead solely to individual use" (Roe, 2000: 17). More than one-third of the teenage research population of d'Haenens et al. (2001) confirms watching TV almost every time with family members, although this number decreases when teenagers grow older. The majority of teenagers, $68 \%$, indicate they prefer to watch their favorite television program with others, preferably with a family member (Pasquier, 2001; Livingstone, 2002). This means that media are integrated into the collective dynamics with parents and siblings (Roe, 2000; Van Rompaey, 2002) and that 'family television' remains strong (Livingstone, 2007). During this family time, where a TV set is literally standing in the middle or in a central place in the family room, people come together and share interests, pleasure and conflicts. Even when teenagers and their families are asked for the ideal position of several multimedia in their dream house, television remains the most important focus of the family home and is positioned central in the living-room with sofas pointing towards it (Van Rompaey and Roe, 2001: 360). Family members simply like to spend time in each other's company and TV viewing is one possible way to come together (Van den Bulck et al., 2000; Van den Broeck et al., 2007) and increase the family's fund of shared experiences and interests (Kubey and Donovan, 2001). Pasquier (2001) articulates that TV viewing is shaped by family routines and is, at the same time, changing them. He even proclaims that "[...] media increase the attractiveness of homes as a place of leisure and reshape the social organization of family life" (Pasquier, 2001: 162).

Female teenagers tend to watch their favorite program more within the company of someone else - mostly their mother; boys, on the other hand, prefer watching their favorite TV show alone (Roe, 2000; d'Haenens et al., 2001; Pasquier, 2001). The study by Pasquier et al. (1998) shows that interaction around media strengthens links between certain family members: a strong mother-daughter bond was found around TV, male siblings tend to play video games together and son-father links are centered around the PC. The results of Bovill and Livingstone's survey (2001) show that teenagers with their own television set are more likely to watch their favorite program alone and it may be that a more private TV access leads to more solitary viewing.

Due to the aforementioned media-bedroom culture, teens are exposed to media messages for more than one-third of the day (Mastronardi, 2003). Media, and more specifically television, is often the subject of talk between parents and their children. According to Pasquier et al. (1998: 511) "talking about media is, of course, another important dimension of family dynamics around media." Out of French, Flemish and Swedish teenagers, Flemish youngsters talk the most with their mother or father. Moreover, talking about television appears to be a recurring daily activity, especially between teens and their mother, more specifically for girls (d'Haenens et al., 2001). Parents are more likely to talk about programs when their children do not have private access to a TV (Bovill and Livingstone, 2001). According to Livingstone 
(2002), the majority of teenagers talk about media with their friends, and these conversations are most often centered around television and then music (and computer games for boys). Seuss et al. (1998) confirmed its integration in social settings with friends in at least three ways, being (1) communal use, (2) themes of conversations, and (3) the strengthening of relationships resulting in a sense of a group identity. We can conclude that media play an important role in routine contacts between friends and family members (see Livingstone, 2002). In order to provide consistency with previous research (e.g. Roe, 2000), the analysis incorporates the factors age and type of education (e.g. general, technical, vocational education) besides gender.

$R Q 3 a:$ What are the singular and combined effects of gender, age and different social and spatial contexts on television-viewing gratification items?

$R Q 3 b:$ What are the singular and combined effects of gender, age and education type on television-viewing gratification items?

\section{Methodology}

Sampling procedure and description of quantitative research

Our study analyzes the spatial and social context of television viewing within the family context of teenagers (aged 14-19) in Flanders by means of a self-report questionnaire with closed- and open-ended questions. Quantitative research methods were chosen in order to provide a broad, general overview of contemporary youths television usage. A stratified sampling procedure was used to ensure that our sample, which consisted of 1555 respondents between the ages of 14 and 19, reflected the distribution of adolescents per province and school type in Flanders. We sent request letters for survey participation to the school boards of 12 selected cities in the five provinces of Flanders. 15 schools decided to participate. Subsequently, we asked the school coordinators to select the participating classes based on their level of education and grade. All participating schools were visited by a researcher in November 2009. Respondents were asked to fill out the survey ${ }^{1}$ (paper and pencil). This procedure took approximately 30 minutes and full anonymity was guaranteed. To avoid respondent fatigue, we chose to restrict the survey content. Data analysis was performed using the software packages SPSS 16 and Latent Gold 4.5.

Males represent $51 \%$ of our sample and females $49 \%(N=1555)$. The mean age is 16.09 years $(S D=1.325)$. Of all respondents: $48 \%$ are in the third and the fourth grade of high school (high school level 2: $N=765 ; M=15.95 ; S D=1.29$ ) and $52 \%$ are in the fifth and sixth grade of high school (high school level 3: $N=790 ; M=16.23 ; S D=1.35$ ). Forty-two percent attend general secondary education, $32 \%$ technical secondary education, $25 \%$ vocational secondary education and $2 \%$ secondary art education $^{2}$. Ninety-three percent of our research population has the Belgian nationality. By means of a three-dimensional weighing procedure based on official figures on gender, age and education type, data are adjusted to the actual Flemish high school population (Departement Onderwijs, 2009).

\section{Survey content}

\footnotetext{
${ }^{1}$ Our questionnaires were pretested to 50 teenagers at different education levels and grades.

${ }^{2}$ Due to the small proportion in the education population, art education will be dropped in the analyses concerning education type. For example the number of art pupils is too low to meet up with cell requirements in GLM analyses.
} 
Media usage. The media usage concept used in this study measured how much time the respondent spent on different old and new media the previous day. Since contemporary media usage is overly typified by multitasking, respondents reported on a 5-point Likert scale (ranging from 1 never to 5 always) as to which type and how many other activities and media practices were combined with television viewing.

Television-viewing gratification. The questionnaire contained a 13-item U\&G scale ${ }^{3}$ derived from Katz et al. (1974) measuring the gratification items respondents seek from watching television. A PCA analysis with oblique rotation was performed on this scale to identify 5 television-viewing gratification items: exploration, amusement, knowledge, social inclusion and escapism.

Spatial and social context. To provide insights into the spatial and social context of teenage television watching, respondents were asked if they preferred watching television within shared family spaces or in their own room. Furthermore, they reported with whom they watched television and who held the remote control within their domestic context.

Television-centered communication. This concept was measured by asking with whom (parents, siblings, friends, stepparents/guardians or boy or girlfriend) adolescents talked about television and television programs. Subsequently, the content of the television-centered communication was evaluated by means of a set of five dichotomous variables.

Demographics. Gender, age and education type were included in the analysis. Other demographics were measured (e.g. education level, residence, nationality) but only used as descriptive variables.

\section{Sampling procedure and description of qualitative research}

Six focus groups ${ }^{4}(\mathrm{~N}=34)$ were conducted in schools, youth clubs and youth movements. Consistency with the sampling procedure of the quantitative part is provided since respondents were chosen on the basis of age, gender and education type. Each focus group consisted of six to eight respondents because this yields satisfactory outcomes in terms of group dynamics (Morgan and Krueger, 1999). Participants were friends or classmates and had known each other for years thus constituting a natural peer group. The small group size allowed for group dynamics and for a degree of depth and complexity in the discussion, as well as intimacy among the participants. Each group conversation -that followed a semi-structured topic list- took approximately 1 hour. Respondents were asked to talk about the spatial and social context of their television-centered communication. All conversations were recorded and transcribed afterwards. The transcribed texts were then critically analyzed by deductive, iterative thematic ${ }^{5}$ coding.

\section{Results}

\section{Television within the context of general media use}

To situate the use of television within the broader context of general media use, respondents were firstly asked to report how much time they spent on media usage the previous day. A multi-dimensional

\footnotetext{
${ }^{3}$ For this 13-item U\&G scale, see Table 1: Rotated solution factor analysis: television-viewing gratification items (structure matrix) page XXX.

${ }^{4} 13$ participants were female, 21 were male.

${ }^{5}$ Based on the themes in the topic list: TV access, spatial viewing, social viewing and TV talk.
} 
unfolding (PREFSCAL) procedure was used on this data, yielding a very close-fitting, parsimonious model (Young's S-Stress = .00, Dispersion Accounted For $=1.00$; figure 1). The plot in figure one is based on the relative frequencies of media usage in the total sample. The relative distance between a medium and a frequency category reflects the proportion of teenagers who reported having used a specific medium for a given time span the day before the survey was administered. The results indicate that watching TV is by far the most popular type of media usage in the sample: $9.1 \%$ did not watch TV the previous day at all, $25.78 \%$ 0-1 hour, $34.3 \%$ 1-2 hours, $16.3 \%$ 2-3 hours and 14.4\% watched 3 hours or more. In contrast, activities involving print media such as reading magazines (67\%), newspapers (68\%) and books (69\%) are clearly situated in the proximity of 0 hours. Still, one-fourth to one-third of the sample reports to have read the previous day. Video gaming on either PC or game console appears to be equally rare: respectively, $65 \%$ and $78 \%$ of the sample did not game. However, a hard core of 5-9\% played for more than 2 hours. Forty-three percent listened to the radio for a maximum of 1 hour, while $53 \%$ used an MP3 player for a span of 0-2 hours. Hardly surprising is the finding of $40 \%$ of the sample engaging in web-surfing and social networking for $>0-1$ hour a day.

\section{Figure 1: Parsimonious model: TV within context of general media use}

In order to look for gender differences, Mann-Whitney U-tests were computed. This nonparametric statistical procedure tests for differences in ordinal data between two independent samples. A significant $U$ indicates that such a difference exists. The results show that boys spent significantly more time reading newspapers $(U=229769, p<.005)$, listening to MP3 players $(U=422125, p<.001)$, playing PC games $(U$ $=175060, p<.001)$, playing console games $(U=187202, p<.001)$ and surfing the web $(U=236691, p$ $<.05)$. On the other hand, girls spent more time reading magazines $(U=210941, p<.001)$, listening to the radio $(U=224981, p<.005)$ and using social-network sites $(U=226179, p<.001)$. Other activities, among which is watching television, do not differ significantly for gender.

However, as pointed out in the literature section, contemporary media usage is overly characterized by multitasking. The data from our survey, fit in an additional model (Young's S-Stress $=.0000104$, Dispersion Accounted For $=1.00$; figure 2), confirm this phenomenon. While the majority of the respondents claim they never combine gaming (52\%), reading (49\%) and listening to music (48\%) with watching television, other activities such as using a cell phone (29\%), online chatting (22\%), surfing the web (24\%) and using social-network sites (21\%) are most of the time combined with watching television. In fact, no less than $17 \%$ claim always to use a cell phone while watching television.

\section{Figure 2: Additional model: TV and multitasking}

Furthermore, multitasking appears to be gendered as girls combine watching TV with reading $(U=181159, p<.001)$, using social-network sites $(U=224933, p<.001)$ and cell phones $(U=202565$ $p<.001)$. Boys, on the other hand, tend to game more often while watching TV $(U=168171, p<.001)$.

\section{Television-viewing gratification items}

To determine the gratification items obtained from television usage in our sample, a set of 13 attributes was factor analyzed using a Principal Component extraction method combined with an oblique rotation. This technique is generally used to reduce a number of variables to a smaller set of components, which

reflect latent structures within the data. Both the KMO (.74) and Barlett's Test of Spherity $\left(\chi^{2}(78)=4829\right.$, 
$p<.001)$ indicate that the data are suitable for factor analysis. A total of five components are extracted, each having Eigenvalues that exceed one. The rotated solution, summarized in table 1, accounts for $68 \%$ of the variance in the initial item pool.

Table 1: Rotated solution factor analysis: television-viewing gratification items (structure matrix)

As the factors' reliability estimates (coefficient $\alpha$ ) equal or exceed .60 , the respective items were coded into the following composite variables: exploration $(M=1.94, S D=.87)$, amusement $(M=4.04, S D=$ $.65)$, knowledge $(M=2.78, S D=.97)$, escapism $(M=2.88, S D=1)$ and social inclusion $(M=2.21, S D=$ .91). Although an $\alpha$-value of .70 is usually regarded as a lower-bound criterion, .60 is deemed acceptable in research, especially when the number of items is limited. Moreover, the factor structure's composition and content are in line with the U\&G tradition (Katz et al., 1974).

Next, the gratification scores were compared for gender and age, using General Linear Model (GLM) analysis. Age was dichotomized using the variable's median, which equals 16 years. A two-way MANOVA was computed for the five gratification variables. MANOVA is a multivariate procedure to test for significant main (and interaction) effects of one or more categorical variables (factors; in this case gender and age group) on a number of dependent variables at interval level (the gratifications). Employing a Bonferroni adjusted alpha of .01 , a main effect of gender is found for exploration $(F(1,1381)=16.63, p$ $\left.<.001, \eta^{2}=.01\right)$, escapism $\left(F(1,1381)=16.37, p<.001, \eta^{2}=.01\right)$ and social inclusion $(F(1,1381)=$ $\left.8.51, p<.005, \eta^{2}=.01\right)$. More specifically, girls have slightly higher scores for exploration and escapism, while boys score higher for social inclusion. Further, significant main effects were found for age on amusement $\left(F(1,1381)=8.82, p<.005, \eta^{2}=.01\right)$, knowledge $\left(F(1,1381)=32.13, p<.001, \eta^{2}=.02\right)$, escapism $\left(F(1,1381)=10.69, p<.001, \eta^{2}=.01\right)$ and social inclusion $\left(F(1,1381)=12.23, p<.005, \eta^{2}=\right.$ .01 ). Older teenagers share lower rates of amusement, social inclusion and escapism, while scoring higher for knowledge. Due to omitting art education, a separate one-way ANOVA was computed for education level (general, vocational en technical education). A main effect of education type is found on both amusement $\left(F(1,1297)=14.35, p<.001, \eta^{2}=.02\right)$ and exploration $\left(F(1,1297)=5.81, p<.005, \eta^{2}=.01\right)$. The figures show teenagers in vocational education to have lower scores for amusement than those in both general and technical education. Also, teenagers in general education have higher surveillance scores than those in vocational education.

\section{The spatial and social context of watching television}

\section{Spatial context}

On average, the respondents have $2.54(S D=1.19)$ television sets at home. Fifty percent have a TV in the bedroom, of which $57 \%$ are boys, implying a significant gender difference $\left(\chi^{2}(1)=24.73 p<.001\right)$. However, $64 \%$ of the teenagers with a bedroom screen - boys and girls alike - spend most of the time watching television in the living room. Moreover, a Kruskal-Wallis Test $\left(\chi^{2}(2)=15.64 p<.001\right)$ points out that teenagers who mostly watch television in their own bedroom reported the highest viewing frequency the day before the survey was administered. Teenagers with a television of their own, still claiming to spend most of their television viewing time in the living room, share higher viewing frequencies than teenagers without their own set. Also, a MANOVA (gender*age*spatial context) was computed for the five gratification variables. Yet, no main effect of spatial context, or interactions with 
age, or gender were found. Likewise, a separate analysis incorporating education type instead of age (gender*education type*spatial context) showed no significant interaction effects.

\section{Social context}

To grasp the social context of television viewing, the respondents were asked whether they usually watched TV at home in the company of their parents, siblings, friends, boy/girlfriend and/or by themselves. Also, they were asked to indicate who usually held the remote control, reflecting the mechanism of negotiating program choice. The data from these questions were then subjected to a Latent Class Analysis (LCA), a technique that allows for the identification of latent structures - or conditionally independent classes - within nominal or categorical data. A standard approach is to test for an increasing number of classes until an acceptable model fit is reached. In the case of social viewing, an insignificant $L^{2}(110)=128.39(p>.05, N$ par $=49$, BIC $=12286)$, indicating a model fit, was found with five latent classes. The information in table 2 summarizes the response probabilities per class.

Table 2: LCA-Social presence classes

Social presence class 1 is characterized by family viewing, given the high probabilities of watching together with their parents $(p=1.00)$ and siblings $(p=.76)$. There is a $43 \%$ chance of the parents holding the remote control and $29 \%$ chance of a joint decision. Social presence class 2 consists of omnibus viewers, sharing high probabilities for all possible viewing partners $(p=.70-.90)$, except for watching together with a boy or girlfriend $(p=.39)$. Social presence class 3 is made up by solitary viewers: they have a $98 \%$ chance of watching alone, while the probabilities of other partners vary between .01 and .33 . Also, they have the highest chance of having the remote control for themselves $(p=.40)$. Social presence class 4 has the highest chance of watching TV with their brother(s) or sister(s). Likewise, their siblings have the highest chance of holding the remote $(p=.27)$. Finally, social presence class 5 is characterized by small chances of watching with anyone, expect for their boy/girlfriend $(p=.76)$. This small chance of watching with siblings and the null chance of siblings holding the remote control is likely to indicate an only child.

Qualitative audience research indicates that watching television is a family activity where parents and children come together. A lot of respondents say they enjoy this family time, like this 18-year-old girl who says that Sunday evenings are the ultimate family moment: "On Sunday evenings, everyone gathers in the living room to watch television,... it's very cosy and a nice way to end your weekend". Some respondents point at conditions that need to be fulfilled in order to watch television in the company of their parents or siblings. Firstly, it depends on the program that is watched and the shared interest in it. Certain programs are 'family territory' because they are mandatory (e.g. the news) or because they gradually became a naturalized family habit as a 17-year old boy explains: "From childhood on, we watch 'Familie (Family)' (soap) together, it's just a habit." Familial watching is often structured according to an 'open house' principle where joint viewing depends on the like or dislike of other family members. The viewing situation of this 18-year old female illustrates this 'open house' principle: "We don't really watch much television at home together. It's more like someone wants to see a program and then someone else does something different, but together... no, not that much. Once in awhile, like the news, for instance, we watch together, when we have time for it and are all at home. But generally speaking, we don't really watch much television together." 
Respondents having a solitary viewing profile (social presence class 3) say they watch alone because their parents prefer a different program. "When my parents watch a film or program that I don't want to see, I just go upstairs and take my laptop to watch a DVD or television series" (female, 16). Another explanation is a lower television attendance as, mainly male respondents, say that other social activities are more important than watching television as an 18-year-old boy says: "I would never stay at home to watch television if I have other options such as going out with friends, or playing soccer!" Here, age can be a possible determinant as older respondents have more freedom of movement in their spare time than younger respondents and older teenagers may value friends, going out together and social contacts more than younger ones. Self-evidently, adolescents who are only child more often watch alone as a 15 year old female indicates: "I always watch television upstairs in my room. My parents hardly watch television and I don't have a brother or a sister... so I watch alone..."

Also, it is important to denote gender differences among the social presence classes. The first two classes, sharing a social-viewing profile, are made up by a majority of girls. Classes 3-5, characterized by more solitary viewing, are composed of a majority of boys (especially solitary class 3 ).

A three-way MANOVA (gender*age*social presence class) yields a significant main effect of social presence for amusement $\left(F(4,1209)=3.58, p<.01, \eta^{2}=.01\right)$. More specifically, social presence class 2 (omnibus viewers) and class 3 (solitary viewers) both have significantly higher amusement scores than class 5 (solitary viewers except for boy or girlfriend). Also, an interaction effect for gender*social presence class is found for knowledge $\left(F(4,1209)=4.69, p<.001, \eta^{2}=.02\right)$. Figure 3 shows that, although boys generally tend to have marginally higher knowledge scores, girls with higher probabilities of watching television in the presence of their siblings (social presence class 4 ), have significantly scored higher on knowledge than boys.

\section{Figure 3: Gendered differences within social presence classes}

Moreover, a significant interaction effect of gender*age*social presence class is found for exploration $\left.F(4,1209)=3.47, p<.01, \eta^{2}=.01\right)$. Figure 4 indicates that older female teenagers, situated in social presence class 4 (watch television with siblings) report significantly higher rates of exploration in contrast to girls of a younger age and boys in the same social presence class.

\section{Figure 4: Interaction effect gender*age* social presence}

An example from one of the focus groups illustrates this tendency for higher exploration scores among older female teenagers:

Female, 19 : "Sex and the City is awesome, I like to watch it because it's funny but mainly because I like the portrayal of friendship among those four girls. I sometimes recognize myself and my own life in that series. My younger sister thinks it's silly if I ask her which 'Sex and the City' character she thinks I resemble the most." 
Finally, an additional MANOVA was computed (gender*education type*social presence class), however yielding no additional significant interaction effects.

\section{Television-centred communication}

To identify patterns of with whom teenagers communicate about television, a second LCA analysis, based on six dichotomous variables, was performed. These variables measured whether teenagers talk with friends, mother, father, siblings, step-parents/guardian and boy or girlfriend about what they have seen on television. A model fit is established with four latent classes $\left(L^{2}(36)=47.47 p>.05\right.$, Npar $=27$, BIC $=$ 8215; table 3).

\section{Table 3: LCA- Television centred communication classes}

Communication class 1 consists of a majority of teenagers who are remarkably communicative about what they have seen on TV. They share probabilities ranging from .81-.99 of talking with their friends, parents, siblings and boy/girlfriend. Communication class 2 is very similar to the first, except for the opposite chance of talking with a boy or girlfriend $(p=.04)$. Communication class 3 contains teenagers who are less likely to talk to their mother $(p=.36)$ and father $(p=.04)$. On the other hand, they are likely to talk with friends $(p=.97)$ about what they have seen on TV. Communication class 4 is made up by a small minority of teenagers who appear not to communicate about what they have seen on TV ( $p=.01-.33)$.

As with social presence, patterns of social interaction appear to be the subject of gender differences. Communication classes 1 and 2, reflecting high probabilities of communication, are composed of a small majority of girls. Less communicative classes (3 and especially 4) are made up by a large majority of boys. In addition, these classes differ significantly for the time spent on watching television the day before filling out the questionnaire. Especially class 4 is characterized by a lower frequency of TV viewing.

Also, significant associations $(p<.005)$ are found between communication and social presence. Social presence class 1 , containing family viewers, is positively associated with communication class 1 ( $\phi=.17$, $p<.001)$ and negatively related to less communicative classes $3(\phi=-.12, p<.001)$ and $4(\phi=.08, p<$ $.005)$. Solitary viewing (presence class 3 ) is negatively associated with communication class 1 ( $\phi=.13, p$ $<.001)$ and positively related to the class of teenagers that hardly engages in communication about television (Class $4 ;(\phi=.12, p<.001)$. Social presence class 5 (watching with boy/girlfriend) is positively associated with communication class $1(\phi=.18, p<.001)$ but negatively related to the other communicative class $2(\phi=.26, p<.001)$. In fact, this makes sense given the difference between both communication classes in probabilities of viewing with their boy/girlfriend.

The focus group analysis reveals that in a lot of families, television is a frequent conversation topic. TV talk and social presence are associated as watching together implies talking together. "I often talk with my mother and sisters about the program on VT4 'Tienermoeders(teenage moms)'. But generally, when we watch programs together, we always talk about them"(Female, 17).

Communicating about television also depends on television attendance: respondents with a low viewing frequency are naturally not communicative about programs. Respondents stress that television related communication at home mainly occurs during familial diners or while watching a certain program, though this is not always appreciated by parents as some teenagers say they can only talk during commercials. 
Some respondents postulate that parents warn for what they call 'bad television' (mainly reality shows) and that a lot of discussions at home are structured round this theme. "When I'm watching 'Temptation Island' or 'De Pfaffs' and my parents see this, they laugh at me and say that I'm watching 'bad television' while I'm only watching it for fun." (Female, 16). In one focus group, the issue of quality is addressed literally: "Well, most of the time, the programs broadcasted on éen are assumed to be high quality programs. And VT4 airs programs like 'The Block' or 'Mijn Restaurant (My Restaurant)', or reality television, and my parents don't think this is interesting television (female, 18). Another reason to talk about television, is when a family member has missed a program and wants to be updated on what happened.

Some respondents clearly state not to communicate about television at home (cf. Communication class 4). When asked why, some say that they always watch alone, so they have nobody to talk to. Others stress that television programs are stupid and irrelevant to talk about. Also, some say they only talk about TV with friends because their parents watch programs and series they do not. Saliently, male respondents are less communicative about television within their familial context than female respondents.

In general, adolescents frequently converse about television programs at school and among friends, especially when a televised event resembles to an actual or potential everyday life situation. A 17-year-old girl says: "I talk about television programs when something happened that I can link to things that happen in my own life..." Almost all participants find it difficult or annoying when they cannot participate in conversations about television series they do not watch, though boys initially are more reluctant to admit they do than girls. That is why they would initiate watching a program when they hear friends talk about it, not to conform, but because they are curious. They would only continue watching the program if they find it amusing or interesting themselves.

A three-way MANOVA (gender*age*communication class) shows a main effect of communication partner for amusement $\left(F(3,1262)=16.66, p<.001, \eta^{2}=.04\right)$, social inclusion $(F(3,1262)=8.89$, $\left.p<.001, \eta^{2}=.02\right)$ and exploration $\left(F(3,1262)=11.69, p<.001, \eta^{2}=.03\right)$ (See figure 5). Post-hoc analysis points out that the means for amusement differ among all classes, except for communication class 1 and 2. Hence, these classes only differ in the likelihood of talking to a boy/girlfriend. For escapism, class 1 and 2 , who share high probabilities of communicating about television, score significantly higher than the less communicative class 3 and 4. Concerning exploration, class 1 differs from class 3-4 and class 2 differs from class 3. An additional MANOVA (gender*education type*communication class) yields no additional significant interaction effects.

Figure 5: Main effects on gratification items for gender*communication class

Next, a third LCA was performed on a set of five dichotomous variables measuring the subject of television-centred communication (table 4$)$. This analysis yields a model fit with four classes $\left(L^{2}(8)=\right.$ $11.48, p>.05, \mathrm{Npar}=23, \mathrm{BIC}=9011)$. Subject class 1 has a high probability $(p=.93)$ of talking about a program's previous episode and a moderate probability of talking about quotes and jokes $(p=.59)$. Subject class 2 is actually quite similar, although there is a higher chance of talking about quotes $(p=.82)$ and a very small chance of talking about the next episode $(p=.08)$. Subject class 3 , made up by a majority 
of boys, has a low chance overall of talking about television programs, except for the previous episode category and some quotes $(p=.62-.65)$. Moreover, this class has a significantly lower television-viewing frequency than the other classes. Subject class 4 , which consists of a majority of girls, is characterized by overall high probabilities of talking about each possible subject $(p=.61-1.00)$.

Table 4: LCA-Subject classes

Furthermore, evidence of contingencies between the communication partner and topic was found. Subject class 3 , entailing the lowest probabilities of talking about various topics, is negatively associated to more communicative classes (communication class 1, $\phi=.13, p<.001$ and class $2, \phi=.07, p<.05$ ). However, positive relations are found with less communicative classes (communication class $3, \phi=.10, p<.001$ and class $4, \phi=.29, p<.001)$.

Group interview data analysis reveals that the subject of television related conversations depends on the discussion partner and the program 'genre'. "With my brother, I often talk about attractive actresses, but I would never do that with my mother for instance" (male, 15). The detective genre provokes different conversation topics than a melodrama for instance: "During CSI (detective genre), we often guess who the murderer will be" (female, 16). Recurrent themes are (appealing) actors/actresses, acting performances, events and (love) story lines, funny quotes and events and previous and next episodes. In one focus group, participants say they discuss the authenticity and sense of reality of certain programs: "During lunch break, we recently discussed the telenovela 'Sara'. Some say it is too 'sugary' and unrealistic, while others are real fans and say it is realistic and recognizable." (male, 16). These conversations designate that adolescents critically question the conventions of the medium and the genre and can thus be considered as literate viewers. A three-way MANOVA (gender*age*subject class) yields no significant interaction effects. However, the main effects of subject class are found for all five gratification scores: exploration $\left(F(3,1357)=11.58, p<.001, \eta^{2}=.03\right)$, amusement $\left(F(3,1357)=15.82, p<.001, \eta^{2}=.04\right)$, knowledge $\left(F(3,1357)=4.39, p<.001, \eta^{2}=.01\right)$, escapism $\left(F(3,1357)=12.46, p<.001, \eta^{2}=.03\right)$ and social inclusion $\left(F(3,1357)=12.08, p<.001, \eta^{2}=.03\right)($ see figure 6$)$.

Post-hoc testing reveals that on the one hand subject class 4, consisting of teenagers who share high probabilities of communicating about all included subjects, has significantly higher gratification scores (except for knowledge). On the other hand, subject class 3, which has the lowest probabilities of talking about a variety of topics, has the lowest gratification scores (again, except for knowledge). Subject classes 1 and 2 are situated in between, whereas class 2 has higher gratification scores than class 3 (again, except for knowledge). In sum, these results indicate that higher probabilities over talking about various subjects are associated with higher gratification scores.

Finally, a three-way MANOVA (gender*education type*subject class) was computed, which did not reveal any additional significant interaction effects.

Figure 6: Main effects on gratification items for gender* subject class

\section{Discussion and conclusion}


A plethora of media goods is registered in our Flemish population. Teens report having $2.54 \mathrm{TV}$ sets at home, spread throughout the house and bedrooms. One out of two teenagers has their own private TV set, which shows an increase in private TV access since 2001 (see d'Haenens et al., 2001. Significant gender differences confirm previous findings: $57 \%$ of boys have their own TV set, in contrast to $43 \%$ of girls. Other 'old' and 'new' media have been successfully integrated in teens' lives, e.g. $40 \%$ reported having engaged in web surfing and social networking the previous day. Listening to music still remains popular, in contrast to print media, which is the least popular media among teenagers. This is, once again, a confirmation of Roe's findings (2000). Although Roe also suggested that boys do not show much interest in reading newspapers, our results counter this idea. No gender-related difference was found for TV viewing, which remains the most popular type of media usage, and has become an integrated part in the daily routine of using media. This habitual media usage is characterized by multitasking. Mobile phones and Internet-related activities are most of the time combined with watching TV and there is a group of $17 \%$ that always uses their cell phone while watching TV. Incorporating gender into the analysis revealed that girls combine TV with reading, using social-network sites and cell phones, while boys prefer gaming in combination with TV-viewing. This can also be linked with the TV-viewing gratification items: girls have higher scores for exploration and escapism, while boys seek social inclusion as the main reason for watching TV. Moreover, age is also a significant determinant for gratification scores, as older teenagers (aged 17-19) share lower rates of amusement, social inclusion and escapism, while sharing higher rates for knowledge than their younger counterparts. This can be explained by the fact that older teenagers watch television less frequently because of their engagement in other, more outdoor leisure activities. Consistent with literature, older adolescents have higher knowledge scores. Conform Sinnaeve et al. (2006), a main effect of education type on gratification items was found indicating that teenagers in general education score higher on amusement and surveillance than those in vocational education.

The media-rich bedrooms of teenagers could lead to more solitary TV viewing (cf. Livingstone, 2007). However, the majority of Flemish teens (64\%) spend most of the time watching TV in the living room. Those who prefer solitary watching are part of the group of teenagers with the highest viewing frequency. Our qualitative study confirmed the importance of communal TV-viewing therefore we agree with Roe (2000) that these media-rich private islands may lead to more individual media use, but that this does not lead solely to individual use. Specific criteria, like the kind of program or the shared interest in it, have to be fulfilled in order to watch TV in the company of others. Certain interviewees even highlighted that specific programs are mandatory and always watched within the context of the family. Moreover, the Latent Class Analysis which identified several groups that share either a social-viewing profile or a more solitary viewing profile highlighted the importance of gender in this context. The first two classes, sharing a social-viewing profile, are made up by a majority of girls, while on the other hand the majority of solitary viewers are boys. This can most likely be explained by the fact that boys have more private access to TV than girls. But also, girls tend to use media for more escapist reasons than boys, who, in terms of gratification, tend to have marginally higher knowledge scores. However, girls who habitually watch TV together with their siblings have significantly higher knowledge scores than boys. It may be so that girls who watch TV with their siblings, have less to say about what program they watch and that more informative programs are watched together. In addition, older female adolescents (aged 17-19) who mostly watch together with their siblings, report significantly higher scores for exploration as opposed to younger girls and boys of the same social presence class. Interestingly, education type yields no significant interaction effects in terms of social and spatial contexts of television viewing. 
As is to be expected, social presence and television-centered communication are significantly associated: respondents with social-viewing profiles interact more with their television-viewing partners than respondents with solitary viewing profiles. We can conclude that television-centered communication still plays a major role in daily contact and interaction between friends and family members (see Livingstone, 2002). A second LCA revealed four communication classes among the respondents. The first two classes are remarkably communicative with all possible communication partners about what they have seen on television, whereas members of the third (talk only with peers) and fourth (are not communicative) class are much less communicative about television content. TV talk is positively associated with frequencies of watching as less communicative respondents have a lower frequency of TV viewing. Gendered differences are noticeable since girls are highly represented in the high communicative classes, whereas a large majority of boys is represented in the less communicative classes. These findings are consistent with research of d'Haenens et al. (2001) and were confirmed in the focus group interviews. Respondents who are highly communicative about television content have considerably higher amusement, social inclusion and exploration scores than respondents who are less communicative about what they see on television. Gender differences show that girls use TV for more social-interaction reasons than boys (cf. literature) and that boys score higher on TV viewing for social inclusion, as boys like to keep up with the latest events and shows. The third LCA analysis, measuring the subject of television-centered communication, provided evidence for the interrelatedness between communication partner and subject as adolescents who are less communicative about television have the highest chance of not talking about various topics. As was to be expected, because of the substantial communicative character of females compared to males, girls have higher probabilities of talking about any television-related subject than boys. Furthermore, teens with higher probabilities over talking about various subjects have higher gratification scores for all gratification categories. It thus seems that social interaction and talk about television and television content yields more satisfied viewers in terms of needs. Not being able to participate in TV-centered conversations among friends is experienced as difficult or annoying (cf. Seuss et al., 1998). Of course, the degree of communication about programs depends on television attendance, the discussion partner and the program genre. Results of the focus groups indicate that adolescents are able to critically question the conventions of the medium and the genre and can thus be considered as media literate.

We can conclude that the old-medium television still has a prominent position in the lives of young people. Because of the contemporary relevance and changed societal mediated context, we plea for more longitudinal, cross-cultural and comparative research regarding television watching. In line with Livingstone and Bovill (2001) we can conclude that the media - particularly screen media - are playing an increasingly significant role within the more indoor, solitary and peer-oriented bedroom. But despite this increased privatization of television access, which is more obvious for boys than for girls, teenagers still prefer to watch TV in the living room where social interaction and television-centered communication are possible and essential. Girls have higher probabilities of watching television in company and talking with different communication. Female teenagers are thus more present in the social-viewing and highly communicative classes, whereas male teenagers are dominantly present in the solitary viewing classes and in the less communicative classes. By focusing on gender and age, our research fills in the gap in contemporary research about the social and spatial context of TV-viewing adolescents. In this context, Flanders can function as a benchmark and reference point for future cross-cultural research.

\section{Role of the funding source}


Funding, provided by the Research Foundation Flanders ( $F W O$ ), was to give our respondents an incentive in exchange for their participation.

\section{References}

Bovill, M., Livingstone, S., 2001. Bedroom culture and the privatization of media use. In: Livingstone, S., Bovill, M., (Eds.) Children and their changing media environment. A European comparative study. Lawrence Erlbaum Associates, New Jersey, pp. 179-200.

Braun-Courville, D.K., Rojas, M., 2009. Exposure to Sexually Explicit Web Sites and Adolescent Sexual Attitudes and Behaviors. Journal of Adolescent Health 45 (2), 156-62.

Cooper, R., Tang, T., 2009. Predicting audience exposure to television in today's media environment: an empirical integration of active-audience and structural theories. Journal of Broadcasting \& Electronic Media 53 (3), 400-18.

Departement Onderwijs. (2009). Statistisch jaarboek van het Vlaams Onderwijs 2008-2009 [Statistical yearbook of the Flemish Educational System 2008-2009]. Retrieved October 21th, 2010, from http://www.ond.vlaanderen.be/onderwijsstatistieken/2008-2009/0809_027-

047_hoofdstuk_1_algemeenoverzicht.pdf

d'Haenens, L., Kokhuis, M., van Summeren, C., 2001. Kijken of surfen? Mediagebruik van kinderen en adolescenten [Watching or surfing? Media usage of children and adolescents]. Acco, Leuven.

Eggermont, S., 2006. Developmental changes in adolescents' television viewing habits: longitudinal trajectories in a three-wave panel study. Journal of Broadcasting \& Electronic Media 50 (4), 742-61.

IBBT, 2009. Digimeter Wave 1: IBBT - iLab.o.

Johnsson-Smaragdi, U., d'Haenens, L., Krotz, F., Hasebrink, U., 1998. Patterns of old and new media use among young people in Flanders, Germany and Sweden. European Journal of Communication 13 (4), 479501.

Katz, E., Blumler, J., Gurevitch, M., 1974. Utilization of mass communication by the individual. In Blumler, J., Katz, E., (Eds.), The uses of mass communication: Current perspectives on gratifications research. Sage, Beverly Hills CA, pp. 19-34.

Katz, E., Gurevitch, M., Haas, H, 1973. On the use of the mass media for important things. American Sociological Review 38, 164-81.

Kubey, R., Donovan, B.W., 2001. Media and the family. In: Singer, D.G., Singer, J., (Eds.), Handbook of children and the media. Sage, Thousand Oaks, pp. 323-40.

L'Engle, K.L., Brown, J.D., Kenneavy, K., 2006. The mass media are an important context for adolescents' sexual behavior. Journal of Adolescent Health 38, 186-92.

Livingstone, S., 2002. Young people and new media. Sage, London. 
Livingstone, S., 2007. From family television to bedroom culture: young people's media at home. In:

Devereux, E., (Ed.), Media studies. Key issues \& debates. Sage, London, pp. 302-21.

Marshall, S. J., Gorely, T., Biddle, S. J., 2006. A descriptive epidemiology of screen-based media use in youth: a review and critique. Journal of Adolescence 29, 333-49.

Mastronardi, M., 2003. Adolescence and media. Journal of Language and Social Psychology 22 (1), 8393.

Morgan, D.L., Krueger, R.A., 1999. The Focus Group Kit. Sage, London.

Pasquier, D., Buzzi, C., d'Haenens, L., et al., 1998. Family lifestyles and media use patterns. European Journal of Communication 13, 503-19.

Pasquier, D., 2001. Media at home: domestic interactions and regulation. In: Livingstone, S., Bovill, M., (Eds.), Children and their changing media environment. A European comparative study. Lawrence Erlbaum Associates, New Jersey, pp. 161-78.

Roberts, D.F., 2000. Media and youth: access, exposure and privatization. Journal of Adolescent Health 27 (2), 8-14.

Roberts, D.F., Foehr, U.G., 2008. Trends in media use. The Future of Children 18, 11-37.

Roe, K., 2000. Adolescents' media use: a European view. Journal of Adolescent Health 27 (Spring), 1521.

Roe, K., Minnebo, J., 2007. Antecedents of Adolescents' Motives for Television Use. Journal of Broadcasting \& Electronic Media 51 (2), 305-15.

Roe, K., Van den Bulck, J., De Cock, K., Dusart, C., 2001, Het onderwijs in een concurrentiestrijd. Een studie naar de positie van formele leerkanalen in een informele kennismaatschappij [Education in a competitive battle. A study on the position of formal learning channels in an informal knowledge society]. K.U.L., Leuven.

Ruggiero, T. E., 2000. Uses and gratifications theory in the 21st century. Mass Communication \& Society $3(1), 3-37$.

Sinnaeve, I., Schillemans, L., 2006. Thuis tv-kijken, voetballen of naar de jeugdbeweging!? [Watching TV at home, playing soccer or going to the youth movement!?] In Vettenburg, N., Elchardus, M., Walgrave, L., (Red.), Jongeren van nu en straks. Overzicht en synthese van recent jeugdonderzoek in Vlaanderen [Young people: now and later. An overview and synthesis of recent youth research in Flanders]. Lannoo, Leuven, pp. 153-86.

Silverstone, R., 2002. Complicity and Collusion in the Mediation of Everyday Life. New Literary History 33 (autumn), 761-80.

Stevens, F., 2006. Media in het verlengde van het eigen leven. Media in het jeugdonderzoek 2000-2005 [Media as extentions of the private life. Media in youth research 2000-2005]. In Vettenburg, N., 
Elchardus, M., Walgrave, L., (Red.), Jongeren van nu en straks. Overzicht en synthese van recent jeugdonderzoek in Vlaanderen [Young people: now and later. An overview and synthesis of recent youth research in Flanders]. Lannoo, Leuven, pp. 187-220.

Suess, D., Suoninen, A., Garitaonandia, C., et al., 1998. Media use and the relationships of children and teenagers with their peer groups. European Journal of Communication 13, 521-38.

Van Cauwenberge, A., d'Haenens, L., Beentjens, H., 2010. Emerging consumption patterns among young people of traditional and internet platforms in the Low Countries. Observatorio (OBS*) Journal 4 (3), 33552.

Van den Broeck, W., Pierson, J., Lievens, B., 2007. Video-on-demand: towards new viewing practices? Observatorio (OBS*) Journal 3, 23-44.

Van den Bulck, J., Van den Bergh, B., 2000. The influence of perceived parental guidance patterns on children's media use: differences and media displacement. Journal of Broadcasting \& Electronic Media 44 (3), 329-48.

Van Rompaey, V., 2002. Media on/Family off? An integrated quantitative and qualitative investigation into the implications of Information and Communication Technologies (ICT) for family life. Doctoral dissertation. K.U.L., Leuven.

Van Rompaey, V., Roe, K., 2001. The home as a multimedia environment: families' conception of space and the introduction of information and communication technologies in the home. Communications: the European Journal of Communication 26 (4), 351-70. 